\title{
PROCESSOS DE DISCRIMINAÇÃO DE PROFISSIONAIS IMIGRANTES E QUALIFICADAS EM CONTEXTOS LABORAIS TIPICAMENTE MASCULINOS
}

\author{
Ana Filipa Caroalho e Emília Fernandes
}

Escola de Economia e Gestão, Universidade do Minho, Braga, Portugal

\section{Resumo}

O aumento dos fluxos migratórios independentes das mulheres continua a coexistir com profundas desigualdades assentes, nomeadamente, em formas de segregação horizontal, vertical e transversal. Este artigo procura explorar os processos de dupla discriminação - de género e de imigração - tal como são percecionados por um grupo de mulheres imigrantes qualificadas a trabalhar em Portugal nas áreas académicas das engenharias, um contexto tipicamente masculino. A investigação baseia-se num estudo qualitativo e tem como objetivo contribuir para a discussão de como é (ou não é) promovida a igualdade profissional de género, num contexto particular, e retratar a potencial discriminação de género específica que se pode associar à experiência de imigração.

Palavras-chave: mulheres qualificadas imigrantes, contextos tipicamente masculinos, gestão da diversidade, igualdade de oportunidades.

\footnotetext{
Abstract

Discrimination processes of female qualified professionals and immigrants in typically male labour contexts

The increase in female migratory independent flows continues to coexist with deep inequalities based, in particular, in forms of horizontal, vertical and transversal segregation. This article seeks to explore the processes of double discrimination - gender and immigration - as understood by a group of qualified immigrant women working in Portugal in the academic areas of engineering, a typically male context. The research is based on a qualitative study and aims to contribute to the discussion of how is (or is not) promoted the professional gender equality, in a particular context, and portray the potential genderspecific discrimination that can be associated with the immigration experience.
}

Keywords: immigrant qualified women, typical male contexts, diversity management, equality of opportunities.

\section{Resumen}

Procesos de discriminación de profesionales cualificadas y inmigrantes en contextos de trabajo típicamente masculinos

El aumento de flujos migratorios independientes de las mujeres continúa coexistiendo con profundas desigualdades basadas, en particular, en las formas de segregación horizontal, vertical y transversal. Este artículo pretende explorar los procesos de doble discriminación - el de género y de inmigración - tal como son percibidos por un grupo de mujeres inmigrantes calificadas, trabajando en Portugal en las áreas académicas de la ingeniería, un contexto típicamente masculino. La investigación se basa en un estudio cualitativo y tiene como objetivo contribuir a la discusión de cómo es (o no) promovida la igualdad de género profesional, en un contexto particular, y retratar a la 
potencial discriminación de género-específica que se puede asociar con la experiencia de la inmigración.

Palabras-clave: mujeres inmigrantes calificadas, contextos típicamente masculinos, gestión de la diversidad, igualdad de oportunidades.

\section{Introdução}

Uma das áreas com grande reivindicação ao direito à igualdade entre os homens e as mulheres encontra-se relacionada com o contexto de trabalho (Amâncio, 2003).

No que concerne à imigração no contexto de trabalho, importa acrescentar que, embora o trabalhador estrangeiro não seja só percebido no masculino e que as mulheres migrantes já não ocupem uma posição secundária em relação aos homens migrantes, os estudos tendem a não englobar a variável de género como dimensão analítica fundamental para caraterizar a imigração, não atendendo à sua influência nas memórias e identidades das imigrantes para a sua integração em contexto profissional (Miranda, 2009).

Posto isto, e apesar do aumento da participação das mulheres no mercado de trabalho e dos fluxos migratórios terem ganho um caráter feminino independente dos fluxos masculinos do passado, continuam a persistir profundas desigualdades assentes, nomeadamente, em formas de segregação horizontal, vertical e transversal. Este artigo procura explorar os processos de dupla discriminação - de género e de imigração - percecionados por um grupo de mulheres imigrantes qualificadas a trabalhar em Portugal nas áreas académicas das engenharias, um contexto tipicamente masculino. A investigação baseia-se num estudo qualitativo e tem como objetivo contribuir para a discussão de como é (ou não é) promovida a igualdade profissional de género, num contexto particular, e retratar a potencial discriminação de género específica que se pode associar à experiência de imigração.

\section{A discriminação de género nos contextos tipicamente masculinos}

Segundo Maria Abranches (2007), enquanto os significados do masculino se continuam a revelar como universais, tal não acontece com as mulheres e o feminino. As suas representações mostram-se limitadas e particulares, verificando-se a mobilidade dos atributos categoriais apenas no sentido do masculino para o feminino e não no sentido contrário: «a única subcategoria que conserva exclusivamente atributos femininos é a de mulher-mãe (...) os significados de mulheratleta ou mulher-empresária, por exemplo, já se ligam a subcategorias masculinas» (Abranches, 2007: 40). Tal acontece devido a um processo de segregação setorial no mercado de trabalho nacional (Ferreira, 1993; Silva, 2010), em que 
muitas instituições reproduzem desigualdades que se definem através da criação de padrões normativos de género ${ }^{1}$ (Vicente, 2013).

Neste âmbito, Virgínia Ferreira (1993) aponta três tipos de segregação laboral: a horizontal, na medida em que os homens e as mulheres estão colocados em diferentes profissões e setores de atividade; a vertical onde os sexos estão divididos por níveis de qualificação; e a transversal, que coloca mais mulheres em setores e empregadores que praticam salários mais baixos. Estes três tipos de segregação são justificados pelas perceções que a sociedade tem das caraterísticas das mulheres e dos homens: as mulheres surgem associadas a dimensões como a emoção e a sensibilidade, bem como a valores associados à ternura, modéstia, passividade, cooperação e pragmatismo; por seu lado, os homens aparecem associados à imagem do trabalhador, a qual pressupõe um controlo sobre as emoções e uma primazia da racionalidade (Ferreira, 1999; Peterson, 2010; Vicente, 2013)

As mulheres encontram-se, portanto, alocadas em profissões que coincidem com o ideal estereotipado tradicional de feminilidade, enquanto os homens estão socialmente representados como aptos para qualquer tipo de trabalho e/ou função, obtendo assim um maior sucesso em termos salariais e de progressão na carreira (mesmo nas ocupações consideradas tipicamente femininas) (Amâncio e Oliveira, 2002; Santos, 2010). No âmbito da segregação vertical, as gestoras tendem a ser percebidas como demasiado mulheres porque estão associadas a comportamentos emocionais e sensíveis e consequentemente consideradas menos competentes e eficazes no seu trabalho (Loureiro e Cardoso, 2008; Cook e Glass, 2014;). Todavia, quando estas atuam de acordo com as caraterísticas masculinas quando o seu sucesso é assinalado pela agressividade e rigidez - são acusadas de ignorarem a sua faceta feminina (Catalyst, 2007; Peterson, 2010).

Em Portugal, a carreira académica, até meados dos anos oitenta, também se manteve como uma carreira masculina, em que a superioridade dos homens se registava em todos os graus académicos (Araújo, 2003). Hoje em dia os dados mostram que as mulheres são $60 \%$ dos diplomados do ensino superior (INE, 2012). Todavia, o número reduzido de mulheres presentes em posições de prestígio e hierarquicamente mais elevadas não faz justiça ao valor assinalado, nem à expansão das qualificações das mulheres (Silva, 2010). Na verdade, os processos de recrutamento e seleção das mulheres na carreira académica são realizados a partir do princípio da «reprodução da dominação masculina»: estas são selecionadas, nomeadamente, para as «carreiras de base», tendo em conta certas suposições acerca das suas capacidades de organização e das suas baixas aspirações de mobilidade profissional, o que leva à possibilidade de perpetuação do poder

Amâncio define estes estereótipos sociais como «ideologizações de comportamentos e ações de grupos de pessoas, estratificadas segundo critérios socialmente valorizados, traduzindo a representação subjetiva e socialmente partilhada de uma ordem de relações intergrupais» (1993: 132). 
masculino nos níveis hierárquicos superiores (Araújo, 2003). Teresa Carvalho e Maria de Lurdes Machado (2010) referem que a ideia de que as universidades se regem por princípios de igualdade de género é apenas uma forma de ocultar a desigualdade. Tal como nas organizações com fins lucrativos, também aqui a existência de competição faz com que a desigualdade pareça algo natural, o que resulta, muitas vezes, de uma falta de consciência das dinâmicas de género (Carvalho e Machado, 2010).

De acordo com a Eurostat (2015), as mulheres na Europa continuam subrepresentadas na hierarquia das universidades. No contexto nacional, o peso das mulheres em posições de tomada de decisão tem vindo a aumentar, tendo passado de $22 \%$ em 2010 para 30\% em 2014. Todavia, apesar de se verificar um certo aumento, as mulheres continuam sub-representadas nestas posições (Eurostat, 2015). A nível europeu e nacional, os dados também indicam que atualmente as investigadoras continuam sub-representadas na área científica das engenharias, onde a percentagem de mulheres registou uma diminuição de dois pontos percentuais entre 2010 e 2014, tendo passado de 33\% para 31\% (Eurostat, 2015).

Segundo a metáfora do «oleoduto que pinga», o número de mulheres nestas áreas também tende a diminuir devido a perfis e critérios masculinos de seleção e recrutamento (Saavedra, Taveira e Silva, 2010). Além disso, a presença maioritária dos homens - cerca de 72\% - (CIG, 2008; Saavedra, Taveira e Silva, 2010), juntamente com a singularidade da figura das mulheres, faz com que os estereótipos de género sejam ampliados (Carvalho e Machado, 2010; Silva, 2010; Cook e Glass, 2014).

Conclui-se assim que, a par de outras instituições, também os contextos académicos funcionam segundo as caraterísticas do sexo masculino, mantendo uma hegemonia de práticas invisíveis que institucionalizam a dominação do masculino sobre o feminino. Estas são algumas das razões para que os contextos das engenharias continuem a ser considerados como masculinos (Saavedra, Taveira e Silva, 2010; Cook e Glass, 2014).

\section{A invisibilidade das mulheres na (i)migração e a discriminação de género}

Como se mostrou antes, o género é um dos fatores socioculturais que mais pode contribuir para a discriminação das pessoas nos seus contextos de trabalho. Esta situação tende a agravar-se quando acrescida pela experiência migratória. Todavia, os estudos tendem a não englobar a variável de género como dimensão analítica fundamental para caraterizar a imigração (Miranda, 2009).

O paradigma clássico dos processos migratórios apresenta os imigrantes como sendo predominantemente do sexo masculino, surgindo as mulheres como acessórios - «dependentes, migrando na qualidade de esposas, mães ou filhas de migrantes masculinos» (Zlotnik, 1995: 229). Segundo Joana Miranda (2010), só quando os estudos de migração tomam como foco central a família e não o indi- 
víduo é que as mulheres migrantes ganham visibilidade e as migrações passam a ser vistas como uma decisão de estratégia familiar. Com isto, a mulher ganha palavra de decisão, embora diretamente relacionada com uma questão privada (familiar) e nunca profissional.

Torna-se claro o dever de reconsiderar a lógica tradicional do trabalho migrante como simplista e fortemente influenciada pela ideia dominante de que o trabalhador estrangeiro é sempre percebido no masculino (Góis e Marques, 2012). Desta forma, as imigrantes deparam-se com uma dupla discriminação ligada ao género - inserem-se no mercado feminino de trabalho que é por si próprio mais limitado do que o dos homens - e ao seu estatuto de imigrante (Ferreira e Tavares, 1998).

Atualmente, a nível nacional, tem sido feito um esforço de integração laboral direcionado para os pouco ou nada qualificados, onde as mulheres imigrantes apresentam realidades de inserção laboral comuns: profissões com baixos salários, baixo estatuto social, poucas qualificações, sobrecarga de trabalho e a inexistência de contratos laborais (Peixoto et al., 2006). Apesar de ocuparem predominantemente estas posições laborais pouco diferenciadas, é importante mencionar que estas, em média, apresentam qualificações superiores às das mulheres autóctones (Malheiros, Padilla e Rodrigues, 2010). Estes dados mostram que a relação das mulheres imigrantes com os segmentos de trabalho pouco ou nada qualificados acaba por ser a única realidade conhecida a nível nacional (Marques e Góis, 2012; 2014).

Um estudo não nacional de Barbara Czarniawska e Guje Sévon (2006) dá conta de que várias das mulheres que obtiveram as primeiras posições de topo em universidades europeias eram imigrantes. De acordo com as autoras, tal justifica-se atentando às lógicas de alteridade: o género e a etnia, em que a «dupla estranheza» provocada pela ligação entre o género e a etnicidade acaba por provocar uma anulação mútua e permitir que estas mulheres não sejam posicionadas na mesma categoria das mulheres autóctones. Elas escapam, por isso, à sua condição de género e não são simplesmente remetidas para a categoria de «imigrantes» (não sendo percebidas como uma verdadeira «ameaça» ao emprego e ao sucesso dos seus pares masculinos autóctones) porque são, na verdade, mulheres. Todavia, esta situação, embora possa facilitar a sua progressão na carreira, porque acabam por não ser aprisionadas numa categoria específica, está longe de garantir uma situação de conforto e estabilidade psicológica. Segundo as autoras, este grupo de mulheres sofre uma dupla pressão no decorrer da sua construção identitária profissional. Sobressai ainda do referido estudo (Czarniawska e Sevón, 2006) o facto de as mulheres imigrantes académicas optarem por diferentes estratégias de legitimação da sua identidade, que passa por sacrificar um ou outro aspeto da sua «estranheza», isto é, a sua feminilidade ou a sua etnia: por exemplo, acabavam por retornar ao país de origem na esperança de acabar com a vida como «imigrante», quando deixam de ver qualquer hipótese de sucesso social ou profissional na sociedade de acolhimento; ao mesmo tempo, não hesi- 
tam em lutar contra a ideia de que o seu comportamento poderá ser considerado «pouco feminino» e desapropriado (Czarniawska e Sevón, 2006).

Marjana Johansson e Martyna Sliwa (2014) mostram que o ambiente académico se carateriza por uma forte divisão de género, recebendo as mulheres menores salários e tendo menores perspetivas de carreira comparativamente aos homens. Em termos contratuais, de promoções, de condições de trabalho ou de remunerações, estas fazem parte de um grupo considerado como desfavorecido, apesar das políticas de igualdade de oportunidades em vigor (Johansson e Sliwa, 2014). Estas políticas, que têm servido como «véus» protetores de discriminação de género e que tentam transparecer uma igualdade de oportunidades, escondem a realidade desigual entre homens e mulheres e as normas masculinas, onde as mulheres são vistas como não competentes: associadas a determinado tipo de personalidade e percebidas como o género fraco perante a pressão dos horários e dos ritmos de trabalho autoritários. Mesmo em termos de aparência, as mulheres não coincidem com a autoapresentação e imagem séria de trabalho árduo que a academia quer transmitir para o exterior (Johansson e Sliwa, 2014). O mesmo estudo acrescenta que as/os próprias/os estudantes esperam um "professorhomem, possivelmente mais velho e com uma voz nobre». Estes estereótipos mentais provocam nas mulheres a sensação de não estarem à altura perante as expetativas estudantis, acreditando que o trabalho como docente ainda é sustentado por uma norma masculina branca (Johansson e Sliwa, 2014).

Nota-se, portanto, que «ser mulher» e «ser imigrante ou etnicamente diferente» são fortes características que ainda limitam e determinam os percursos profissionais nas sociedades de acolhimento. Assume-se, pois, relevante explorar os processos de discriminação percebidos por um grupo de mulheres qualificadas e imigrantes a trabalhar em Portugal nas áreas académicas das engenharias.

\section{Metodologia}

A metodologia qualitativa é a que mais se adequa ao prosseguimento dos objetivos do estudo. $\mathrm{O}$ foco principal do artigo passa pela construção de um esquema de inteligibilidade sobre o presente contexto empírico: mulheres imigrantes e qualificadas num contexto laboral específico. Atendendo a que o instrumento da metodologia não pode ser escolhido independentemente do conteúdo teórico da investigação e do seu objetivo, optou-se pelo método da entrevista semi-estruturada - uma técnica qualitativa que explora um tema a partir da procura de informações, perceções e experiências de determinadas fontes para analisá-las e apresentá-las de forma estruturada (Quivy e Campenhoudt, 1992). O recurso à revisão bibliográfica foi fundamental para arquitetar um grupo de questões de partida para o guião da entrevista semi-estruturada que se construiu em volta dos seguintes tópicos: 1) Identificação sociodemográfica - idade, naturalidade, concelho de residência atual, estado civil, localização geográfica do tra- 
balho, nível de escolaridade; 2) Situação anterior ao projeto migratório - ano de imigração, tipo de imigração, razões da migração, atividades profissionais no país de origem, condições de trabalho; e 3) Situação em Portugal e contexto laboral - atividades laborais, perceções sobre a atividade profissional atual, ocorrência de situações discriminatórias e de precariedade laboral, fatores de (in)sucesso, dificuldades.

Para efeitos de constituição do grupo de participantes, a presente investigação operacionalizou o conceito de mulheres imigrantes a trabalhar num contexto masculino da seguinte forma: cidadã sem naturalidade portuguesa, nascida no estrangeiro, que adquiriu ou não nacionalidade portuguesa e que atua profissionalmente num contexto académico nacional nas áreas de engenharia.

O passo seguinte foi o de identificar possíveis contactos para a realização da entrevista semiestruturada. Em primeiro lugar, foram contactadas as Ordens de Engenheiros de vários distritos como Vila Real, Viana, Braga, Porto, Lisboa, Setúbal, Faro, Aveiro, Bragança, entre outros, para a identificação de mulheres com o perfil procurado, ainda que esta opção não tenha sido bem-sucedida uma vez que as Ordens recusaram o acesso à informação solicitada.

Como segundo plano, e de forma a tentar simplificar este passo, foram pesquisados via internet os contactos de académicas estrangeiras nas várias universidades do país que se encontrassem a exercer a sua atividade profissional nas áreas científicas de engenharia. Deste modo, foram contactadas as secretarias de várias universidades e elaborada uma extensa pesquisa, via site dos Departamentos e Secções de Engenharias, com vista a recolher informações que auxiliassem na identificação de possíveis participantes. Para finalizar este processo, as académicas imigrantes eram contactadas através do correio eletrónico ou por telefone.

Numa terceira fase foi feita uma pesquisa de investigadores/as do Laboratório Ibérico Internacional de Nanotecnologia localizado em Braga.

Posto isto, a amostra é constituída por 16 entrevistadas, cujos contactos resultaram das várias iniciativas aqui referidas. Este grupo apresenta um perfil diverso ao nível sociodemográfico, com média de idades de 39 anos, sendo a idade mínima de 29 anos e a máxima de 54 anos. Relativamente aos países de origem, estes não se cingem somente ao continente Europeu (Espanha, Alemanha, Bósnia e Herzegovina, República Checa, Hungria e Croácia), mas incluem também profissionais da Coreia do Sul, Irão, China, Colômbia e Tunísia. Apenas duas das entrevistadas têm dupla nacionalidade, sendo portuguesa a segunda nacionalidade.

Das 16 entrevistadas, apenas duas não optaram por Portugal como primeiro país de imigração. A maior parte justifica esta escolha por se terem candidatado a bolsas de pós-Doutoramento da Fundação para a Ciência e Tecnologia (FCT) e terem sido aceites. Outras referiram que foi uma escolha que atendeu a razões familiares, nomeadamente «...ir atrás do meu namorado.» (Ent. 11); «...o meu marido é português e decidimos morar em Portugal.» (Ent. 1). As restantes acabaram por referir outro tipo de fatores decisivos: «A planta de produção da 
minha empresa em Portugal é uma das melhores do grupo.» (Ent. 9); «Portugal está perto do meu país de origem e as culturas são semelhantes.» (Ent. 16); e «Há [pessoas] experientes na minha área com quem eu queria trabalhar.» (Ent. 10). As duas entrevistadas, que não tiveram Portugal como primeira escolha, admitem que pretendiam um país «mais desenvolvido» e «melhor financeiramente».

As entrevistadas chegaram a Portugal entre os anos 1990 e 2013, sendo o ano 2009 o mais representado (5 mulheres). Mais de metade das mulheres entrevistadas iniciaram o seu projeto migratório sozinhas (9). As restantes completaram esta trajetória acompanhadas pelas famílias, nomeadamente, pelos pais (1), maridos e/ou filhos (5). Das 16 participantes, 11 são casadas e apenas 4 têm marido português.

Relativamente à situação profissional atual, as participantes referem ser difícil progredir nas suas carreiras académicas em Portugal, limitando-se, assim, a investir em tarefas pedagógicas e científicas. A maioria das entrevistadas está em Portugal como investigadora (8), identificando-se ainda algumas assistentes de investigação (5) e professoras na carreira académica (3). As participantes encontram-se tendencionalmente em «carreiras de base» (Araújo, 2003: 120) nas universidades portuguesas, estando, por isso, em níveis baixos da hierarquia académica.

\section{Mulheres imigrantes e qualificadas - «uma ficção científica?»}

O obstáculo constantemente levantado pelas entrevistadas prendia-se com o receio de que a confidencialidade não fosse totalmente garantida. As entrevistadas mostraram-se ainda desconfortáveis em serem categorizadas como «estrangeiras», o que nalguns casos se tornou num obstáculo à sua participação.

Durante a pesquisa dos contactos e troca de mensagens via correia eletrónico, ocorreu uma situação involuntária, mas que acabou por ser ilustrativa do estigma associado à condição de imigrante em Portugal. Por lapso, uma das mensagens de apresentação do estudo e solicitação de participação seguiu para um endereço de correio eletrónico de uma professora de nacionalidade portuguesa. Tal equívoco provocou junto da docente um enorme desconforto por ter sido percebida como integrada na categoria de «imigrante», o que conduziu a algumas reações: «Estaremos mais uma vez na história a entrar numa «caça às bruxas» ou teremos outra inquisição?». Mais especificamente, a académica expressou o seu desconforto da seguinte forma:

Os únicos imigrantes que eu conheço trabalham em atividades bem tradicionais, apresentando pouca diversidade. Os homens trabalham nas obras de construção civil ou na recolha de lixo e as mulheres dedicam-se às atividades de limpeza e de serviços domésticos (...) eu formei-me em 1985 e sou membro da Ordem dos Engenheiros desde os meados dos anos 80 . Sou uma participante bastante ativa nos eventos e na vida da Ordem. Nunca vi nenhum imigrante na Ordem. Será que há? Nunca 
vi no meio universitário nenhum «verdadeiro» imigrante na carreira académica. Conheço imigrantes (verdadeiros imigrantes) a trabalharem nas universidades em França, Reino Unido, EUA, etc. Em Portugal não conheço nenhum. Muito menos mulheres-imigrantes. Ainda menos mulheres imigrantes e a trabalharem nas áreas ditas «masculinas». Não será ficção científica?

Neste excerto é visível o desconforto da docente com a categoria de imigrante que ela distancia daquilo que é o seu trajeto pessoal e profissional no contexto nacional. Dir-se-ia que duvida que uma mulher imigrante pudesse ter o mesmo percurso profissional que ela própria por causa dessa sua situação identitária que a parece diminuir e desvalorizar, segundo a docente. Esta atitude permite-nos, em certa medida, explicar a relutância e desconfiança das participantes relativamente à presente investigação.

\section{Processos de discriminação de mulheres imigrantes qualificadas em con- textos tipicamente masculinos}

A nível nacional e em contextos laborais tipicamente masculinos, este grupo de mulheres não deixou de mencionar a discriminação em relação à sua dupla identidade de mulheres e imigrantes. Ao nível contratual e salarial, é possível relacionar a desigualdade de género com a hierarquia académica onde as mulheres referem encontrar o chamado efeito de «teto de vidro» que bloqueia a sua ascensão profissional porque, mediante esta metáfora, as mulheres têm menos probabilidades de serem nomeadas para cargos de liderança do que os seus colegas homens (Catalyst, 2007; Santos, 2010; Cook e Glass, 2014). Deste modo, as participantes apontam ser mais fácil a entrada na carreira de investigação mas mais difícil progredir nas posições académicas ou ocupar posições de destaque e de gestão dentro da academia, principalmente, em situações em que se acrescenta o «estrangeirismo» ao facto de ser mulher - a «dupla estranheza». Dentro desta dificuldade de progressão académica, as participantes também assumem que se um dia essa progressão acontecer será derivada de um processo mais lento e nunca acontecerá tão rapidamente como acontece com os homens. Referem inclusive que na maior parte das situações são deixadas de fora e que «os homens competem entre eles mesmos» (Ent. 9).

Quando são montadas comissões, por exemplo, só escolhem os homens, não que tivesse à espera que me chamassem porque sou estrangeira, mas não vejo outras mulheres lá (Ent. 5);

[Ser] mulher e imigrante causaram que não ganhei nenhum concurso dos vários a que concorri, até que acabei por desistir (Ent. 8). 
Todavia, além de mencionarem situações explícitas de discriminação em relação à sua dupla identidade de mulheres e imigrantes, as participantes tendem a naturalizar e individualizar a discriminação de género, justificando-o com a sua "condição biológica» (Ent. 2). Isto é, a desigualdade de género é desvalorizada pelo facto das participantes serem ou poderem vir a ser mães, o que serve como um fator impeditivo de progressão e causador do efeito de «teto de vidro» (Catalyst, 2007; Santos, 2010; Cook e Glass, 2014).

Se não chegamos tão longe não é por discriminação no local de trabalho, mas porque realmente não temos oportunidade de nos embrenharmos tanto como os homens. Na minha opinião, isto deve-se à nossa própria condição de mulheres (Ent. 2);

O preconceito contra a mulher pode ter diferentes conotações. O simples facto de sermos mulheres não pode ser um obstáculo, mas quando somos uma mulher com obrigações familiares - uma mãe - realmente pode fazer as pessoas pensarem que somos menos orientadas para o trabalho. Geralmente, não há verdade nisso. Mas o valor do trabalho para a mulher torna-se muito mais baixo, em comparação com o de um homem, mesmo que o homem também tenha obrigações familiares - ser pai (Ent. 4);

De alguma forma, aos olhos dos outros, esta situação de ser mãe é percebida como se o meu potencial de trabalho fosse menor do que o das outras pessoas e que eu não possa alcançar tanto ou mais como elas (Ent. 5).

A maternidade surge assim como legitimadora da desigualdade de género. Os homens parecem figuras ausentes desta reflexão sobre as responsabilidades familiares e quando presentes, o seu papel e obrigações parecem não ser questionados. A responsabilidade relativa à discriminação passa assim a ser das próprias mulheres, ou seja, uma responsabilidade individual que iliba a sociedade e os homens enquanto agentes de discriminação (Amâncio, 2003).

Torna-se agora relevante especificar estes processos de desigualdade nas relações com o género oposto nos seus quotidianos de trabalho, onde as participantes na sua maioria estão de acordo com a inexistência de práticas discriminatórias embora haja testemunhos de que «...as pessoas não falam entre elas e que arranjar amigos no ambiente de trabalho não é fácil» (Ent. 6) e que «...não há uma valorização pelos meus colegas de trabalho» (Ent. 8). Ou seja, por um lado apontam não sentir qualquer tipo de discriminação e por outro lado acrescentam que não é fácil serem valorizadas. Este grupo de mulheres parece, assim, estar consciente das «micro desigualdades» (Araújo, 2003) que sofrem no seu dia-a-dia de trabalho: «Tudo é menor para elas» (Ent. 12). Observa-se, ainda, a perceção das participantes de que as mulheres têm de provar na prática que são mais competentes do que os seus colegas homens (Saavedra, Taveira e Silva, 2010). 
A desvalorização da discriminação de género acaba por ser uma consequência da própria sociedade. As participantes parecem assim ter dificuldade em colocar em causa o poder masculino que reforça o poder dos homens que ainda atualmente controlam a maioria dos lugares de topo, consequentemente, este «género forte» irá continuar a manter esta superioridade numérica nas posições de topo e, desta forma, as mulheres são consideradas sempre como as «segundas melhores» (Loureiro e Cardoso, 2008: 224), mesmo que o seu esforço seja o dobro do sexo oposto.

As participantes tendem a «naturalizar» a discriminação, fundamentalmente, ao associarem à sua condição de mulheres-mãe, ao aceitarem que têm que fazer um esforço suplementar e ao fazer uso de uma feminilidade caracterizada pelo estabelecimento de relações afáveis com os seus pares masculinos. Aceitam as regras masculinizadas dos seus quotidianos e criam diferentes estratégias, de forma a superar a sua condição de género enquanto mulheres: mentalizam-se desde o início que não será de todo uma tarefa fácil ao trabalharem nestes contextos e que devem encarar tudo com trabalho duro, persistência e acreditar em pleno nas suas capacidades porque mais ninguém o fará (Ent. 4); tentam criar boas relações com todos os seus colegas de trabalho independentemente do posto hierárquico em que estão alocados (Ent. 9); tentam pensar a longo prazo e criar um terreno mais maleável para as próximas mulheres nesta situação, mantendo a calma, mostrando as suas habilidades e não entrando em discussões com o sexo oposto (Ent. 10); e, por fim, tentam fazer sempre mais e melhor do que os seus colegas homens (Ent. 12).

Deve ficar claro desde o início que não será uma tarefa fácil, e uma vez que você aceitar esse facto, será mais fácil lidar com todos os desafios. Não espere muito apoio e compreensão dos outros, ou esperança de que ele vai ficar mais fácil, em vez disso você precisa confiar em si mesmo e ser determinado, e as coisas vão funcionar (Ent. 4);

Na minha opinião, é importante que tudo comece a tornar-se claro e que se comece a preparar o «terreno» para a seguinte mulher não ter o mesmo tratamento injusto. Para fazê-lo, deve-se ter e mostrar mais habilidades objetivamente em vez de apenas discutir com os homens. Assim, melhorar a si mesmo (Ent. 10);

São reconhecidos ainda como momentos de discriminação de género as situações em que as mulheres são masculinizadas no seu contexto de trabalho: «É mulher, 'mas' vale por dois homens» (Ent. 14). Está-se perante um tipo de discriminação disfarçada por um elogio que enfatiza o masculino como (dupla) norma. Consoante os estudos de Ferreira (1999) quando uma mulher consegue se destacar, a expetativa é sempre maior daquela que se teria com um homem porque esta pertence a um género que a remete para uma situação de desvalorização imediata - «Quando um homem erra, ele é perdoado. Se uma mulher comete o 
mesmo erro, ela é esconjurada» (Ent. 13). Os homens são assim antes de tudo indivíduos e não seres genderizados.

A barreira comunicacional surge como principal constrangimento do dia-adia de trabalho destas mulheres imigrantes. As participantes apontam o "saber falar português» como uma grande ajuda à sua integração: «Eu consigo falar e perceber $80 \%$ da língua e, para mim, isto é um grande avanço em termos de integração» (Ent. 9). Do outro lado, as que não sabem falar português, descrevem experiências diferentes, nomeadamente, surgem barreiras no trabalho e uma dificuldade acrescida em estabelecer relações profissionais com os seus colegas:

Vindo da Europa do sudeste... a maioria das pessoas em cargos administrativos presumem que eu sou uma imigrante com baixas qualificações/baixa escolaridade. Eles ficam irritados e, por vezes, não estão realmente dispostos a explicar lentamente se eu não entender as explicações em primeiro lugar (Ent. 4);

Os meus colegas falam Português nas discussões de trabalho, mesmo em algumas obras sérias que devemos todos estar a par. Eu sinto-me de parte e às vezes acho que eles fazem isso de propósito. Há sempre uma preferência para o Português (...) por vezes, é difícil participar em decisões (Ent. 14).

Esta dificuldade comunicacional, só por si, é suficiente para constituir uma verdadeira «barreira» e criar situações de desconforto, uma vez que faz com que, por exemplo, as entrevistadas não consigam dar a sua opinião e discutir assuntos em processos de tomada de decisão (quando estes são falados somente em português). Aqui, mais uma vez, persiste a dificuldade de progressão académica, agravando-se quando a variável étnica lhe é associada. Na verdade, segundo os testemunhos recolhidos, parece que a condição de estrangeira acentua ou supera a discriminação de género. De uma forma geral, a maior parte das imigrantes aponta que o facto de serem estrangeiras acaba por pesar mais e causar um maior impacto num contexto masculinizado do que o facto de serem mulheres, à exceção de uma das entrevistadas de origem espanhola que considera não ter sofrido dificuldades de integração dadas as semelhanças entre Portugal e o seu país de origem (desde a cultura à língua).

Possivelmente ser imigrante pesa mais do que ser mulher. Em termos de contratação, é provável que um país tenha preferência pelos seus próprios cidadãos (Ent. 1);

Ser imigrante realmente diminui as minhas oportunidades de encontrar um bom emprego, pois, até os meus colegas portugueses lutam por um bom emprego. Não saber perfeitamente a língua portuguesa torna-se realmente um grande obstáculo todos os dias, principalmente na vida profissional (Ent. 4);

A etnia (...). Os portugueses não conseguem distinguir diferentes culturas asiáticas, para eles se veem alguém com os olhos em bico são logo chineses. A maioria dos 
chineses que têm mais amigos dentro da comunidade chinesa é porque falam mal a língua portuguesa (que é difícil de assimilar) e por isso refugiam-se na «sua» comunidade (Ent. 13);

O impacto causado pelo facto de ser imigrante tem indícios mais pejorativos do que o impacto de ser mulher, nestes contextos tipicamente masculinos. A verdade é que há sempre uma condicionante em determinada situação que se impõe mais que outra e, em geral, a barreira linguística encontra-se de mão dada com a forma como estas mulheres imigrantes criam relações e atuam no seu local de trabalho.

\section{Conclusão}

A análise anteriormente descrita permite reconhecer limitações, constrangimentos e desigualdades que serão agora resumidamente retomadas no sentido de identificar algumas sugestões/recomendações para um desenvolvimento e melhoria na integração deste grupo específico de mulheres nestes contextos profissionais também eles específicos.

Afirma-se que, para além de todo o discurso de celebração da igualdade entre os homens e as mulheres, existem evidências que sustentam a conjetura de que as mudanças no mundo laboral ainda não atingiram um nível igualitário de oportunidades e que as desigualdades se agravam quando é introduzida a variável étnica. Todavia, a análise qualitativa desenvolvida na presente investigação aponta ser possível para este grupo de mulheres aqui representado trabalharem num meio laboral considerado tradicionalmente como tipicamente masculino, embora, para tal, elas sejam obrigadas a escolher diferentes estratégias de adaptação (ou até de sobrevivência). Assim, procuram construir o seu espaço de manobra como profissionais a partir de um esforço suplementar no sentido de confirmar a sua competência. Esforço suplementar que os seus pares masculinos não têm que fazer. Além disso, nestes contextos onde se conseguem manter e trabalhar, são percebidas todavia como seres que a ele não pertencem, suscitando inclusive comportamentos paternalistas por parte dos seus colegas homens. Esta é também outra forma de a discriminação de género se manifestar: uma discriminação que passa por um tratamento diferenciado e protetor por parte dos colegas do sexo masculino porque as participantes são mulheres; e uma valorização por parte dos colegas do sexo masculino às suas colegas porque elas valem mais do que «dois homens».

Outro ponto discriminatório está associado à divisão entre o trabalho e a família, onde a maternidade surge como legitimadora da desigualdade de género: a imagem do «chefe de família» (o que coloca o «pão na mesa») ligada aos homens, enquanto a imagem das mulheres é remetida para a sua condição de género enquanto mães e cuidadoras da família. Esta última, que atualmente 
ainda representa as mulheres em geral, acarreta repercussões ao nível profissional como a dificuldade em progredir nas suas carreiras de investigação/académicas, limitando-se a investir em tarefas pedagógicas e científicas. Neste sentido, as mulheres deparam-se com o chamado efeito de «teto de vidro» uma vez que são percebidas como não adequadas para posições hierarquicamente mais altas e incapazes de tomar decisões objetivas (Catalyst, 2007; Santos, 2010; Cook e Glass, 2014). Estas dificuldades de progressão na carreira, bem como no processo de integração e de adaptação, são ampliadas pela condição étnica destas mulheres que, no geral, não se sentem enquadradas no seu local de trabalho. A barreira linguística surge como o elemento mais potenciador desta discriminação étnica. $\mathrm{O}$ não saber falar português é um entrave para algumas das participantes por não conseguirem participar nas tomadas de decisão ou discussões importantes (pontos falados em português), sendo desvalorizadas e deixadas de parte. Claro está que isto provoca uma monotonia laboral sem qualquer esperança de ascensão profissional.

Após sintetizarmos os pontos de desigualdade mais marcantes e sentidos pelo grupo de profissionais em causa é importante agora identificar algumas propostas de desenvolvimento destas limitações subjacentes à dupla estranheza destas mulheres.

Desta forma, o primeiro passo pressupõe manter a opinião do «sensocomum» informada e sensibilizada para estas micro-desigualdades sofridas pelas mulheres imigrantes investigadoras/académicas e que passam despercebidas no nosso dia-a-dia. Para o efeito, é necessário mudar mentalidades num futuro próximo. Esta mudança não deve ser vista como uma responsabilidade individual porque, tal como Loureiro e Cardoso (2008: 228) referem «esta missão apresentase difícil sem a ajuda dos organismos oficiais». Ferreira (1999: 218) acentua: «não podemos esperar que a superação das desigualdades se produza exclusivamente ao nível [micro] e das interações entre mulheres e homens, já que a sociedade se estrutura em torno do princípio da desigualdade ao nível do funcionamento das instituições e da organização da vida social». A sociedade tem assim um papel fundamental no que toca a desigualdades entre os sexos e, acrescenta-se, desigualdades associadas à etnicidade.

A um nível organizacional, sugere-se que se (re)pensem e se (re)definam as políticas de igualdade de oportunidades, tendo em conta as especificidades dos grupos minoritários, as suas experiências de vida e os seus contextos. Neste caso, apresentar um diagnóstico das necessidades deste grupo de profissionais já que a existência de políticas formais familiarizadas como a gestão da diversidade não são suficientes para assegurar avanços nesta matéria, porque mesmo sendo utilizados procedimentos mais formalizados, as práticas discriminatórias continuam a persistir embora estejam encobertas por uma «retórica de objetividade e cientificidade» (Cabral-Cardoso, 2003: 58). A existência de uma política de igualdade de oportunidades é utilizada, muitas vezes, como uma desculpa para dispensar a reflexão ou discussão de atos discriminatórios a um nível micro (Cabral-Cardoso, 2003). 


\section{Referências bibliográficas}

Abranches, Maria (2007), Pertenças fechadas em espaços abertos. Estratégias de (re)construção identitária de mulheres muçulmanas em Portugal, Lisboa, Observatório da Imigração.

Amâncio, Lígia e Oliveira, José Manuel de (2002), «Liberdades condicionais: o conceito do papel sexual revisitado», Sociologia, Problemas e Práticas 40, 45-61.

Amâncio, Lígia (1993), «Género - Representações e Identidades», Sociologia, Problemas e Práticas 14, 127-140.

Amâncio, Lígia (2003), «O género no discurso das ciências sociais», Análise Social 36(168), 687-714.

Araújo, Emília Rodrigues (2003), «A sevícia das categorias: breve contribuição para o estudo dos usos e representações do tempo por parte das mulheres académicas», Cadernos do Noroeste 21(1-2), 107-140.

Cabral-Cardoso, Carlos (2003), A igualdade de oportunidades entre homens e mulheres em contexto empresarial, Braga, Universidade do Minho.

Carvalho, Teresa e Machado, Maria de Lurdes (2010), «Gender and shifts in higher education managerial regimes", Australian Universities' Review 52(2), 33-42.

Catalyst (2007), The double-bind dilemma for women in leadership: Damned if you do, doomed if you don't, New York, IBM Corporation.

CIG (2008), Guião para a implementação de plano de igualdade nas empresas, Lisboa, CIG.

Cook, Alison e Glass, Christy (2014), «Women and top leadership positions: towards an institutional analysis», Gender, Work E Organization 21(1), 91-103.

Czarniawska, Barbara e Sévon, Guje (2006), «The thin end of the wedge: foreign women professors as double strangers in academia», Gender, Work \& Organization 15(3), 235-257.

Eurostat (2015), She figures, [em linha] disponível em https://ec.europa.eu/research/ swafs/pdf/pub_gender_equality/she_figures_2015-leaflet-web.pdf [consultado em 2 de maio de 2016].

Ferreira, Virgínia e Tavares, Teresa (org.) (1998), «Mulheres nos caminhos da diáspora: a construção das identidades e da cidadania na Europa», Revista Crítica de Ciências Sociais 50, 5-14.

Ferreira, Virgínia (1993), «Padrões de segregação das mulheres no emprego - Uma análise do caso português no quadro europeu», in Boaventura Sousa Santos (org.), Portugal: Um retrato singular, Porto, Afrontamento, 233-260.

Ferreira, Virgínia (1999), «Os paradoxos da situação das mulheres em Portugal», Revista Crítica de Ciências Sociais 52/53, 199-227.

Góis, Pedro e Marques, José Carlos (2012), A emergência das migrações no feminino - feminização das migrações de (e para) Portugal e as suas consequências sociopolíticas, Cascais, Princípia.

Góis, Pedro e Marques, José Carlos (2014), Processos de admissão e integração de imigrantes altamente qualificados em Portugal e a sua relação com a migração circular, Lisboa, Observatório da Imigração.

INE (2012), Estatísticas no Feminino: Ser Mulher em Portugal - 2001-2011, Lisboa, Instituto Nacional de Estatística.

Johansson, Marjana e Sliwa, Martyna (2014), «Gender, foreignness and academia: an intersectional analysis of the experiences of foreign women academics in UK Business Schools», Gender, Work E Organization 21(1), 18-36.

Loureiro, Paula e Cardoso, Carlos Cabral (2008), "O género e o estereótipo na gestão», Tékhne - Revista de Estudos Politécnicos VI(10) 221-238.

Malheiros, Jorge, Padilla, Beatriz e Rodrigues, Frederica (2010), Mulheres imigrantes empreendedoras, Lisboa, CIG. 
Miranda, Joana (2009), Mulheres imigrantes em Portugal: memórias, dificuldades de integração e projectos de vida, Lisboa, Observatório da Imigração.

Peixoto, João et al. (2006), Mulheres migrantes: percursos laborais e modos de inserção socioeconómica das imigrantes em Portugal, SOCIUS, ISEG/UTL.

Peterson, Helen (2010), «The gendered construction of technical self-confidence: women's negotiated positions in male dominated, technical work settings», International Journal of Gender, Science and Technology, 66-88.

Quivy, Raymond e Campenhoudt, Luc Van (1992), Manual de investigação em ciências sociais, Lisboa, Gradiva.

Saavedra, Luísa, Taveira, Maria do Céu, e Silva, Alexandra (2010), «A subrepresentatividade das mulheres em áreas tipicamente masculinas: fatores explicativos e pistas para a intervenção», Revista Brasileira de Orientação Profissional 11(1), 49-59.

Santos, Gina Gaio (2010), "Gestão, trabalho e relações sociais de género» in Virgínia Ferreira (org.), A igualdade de mulheres e homens no trabalho e no emprego em Portugal: politicas e circunstâncias, Lisboa, CITE, 99-132.

Silva, Sofia Marques (2010), «Mulheres e feminilidade em culturas ocupacionais de hegemonia masculina», in Virgínia Ferreira (org.), A igualdade de mulheres e homens no trabalho e no emprego em Portugal: políticas e circunstâncias, Lisboa, C ITE, 293-332.

Vicente, Maria Alexandra (2013), O género nas estruturas organizacionais: a diferenciação entre homem e mulher na ocupação de funções, no acesso ao poder e nos salários, Working Paper, 153, CIES.

Zlotnik, Hania (1995), «The South to North Migration of Women», International Migration Review XXIX(1), 229-454.

Ana Filipa Carvalho. Licenciada em Sociologia do Trabalho e Mestre em Gestão de Recursos Humanos, pela Universidade do Minho.

Emília Fernandes. Professora Auxiliar na Escola de Economia e Gestão, da Universidade do Minho e Doutorada em Ciências Empresariais. A sua investigação tem-se centrado na discriminação e igualdade de oportunidades de género; gestão da diversidade; empreendedorismo; práticas de resistência e identidades organizacionais; e gestão de recursos humanos. Tem publicado na área dos estereótipos de género e gestão, identidades femininas empreendedoras e práticas de resistência em contexto organizacional.

Endereço: Emília Fernandes, Escola de Economia e Gestão, Universidade do Minho, Campus de Gualtar, 4710-057 Braga, Portugal. mifernandess@gmail.com

Artigo recebido em 17 de setembro de 2015 e aceite para publicação em 16 de abril de 2016. 